Research Article

\title{
Enhanced Heat Transfer Characteristics of Graphite Concrete and Its Application in Energy Piles
}

\author{
Qingwen Li $\mathbb{D}^{1,2}$ Lu Chen ${ }^{1}{ }^{1}{ }^{1}$ Haotian Ma, ${ }^{1}$ and Chung-Ho Huang ${ }^{3}$ \\ ${ }^{1}$ Department of Civil Engineering, University of Science and Technology Beijing, Beijing, China \\ ${ }^{2}$ State Key Laboratory of Building Safety and Built Environment, China Academy of Building Research, Beijing, China \\ ${ }^{3}$ Department of Civil Engineering, National Taipei University of Technology, Taipei City 10608, Taiwan
}

Correspondence should be addressed to Qingwen Li; qingwenli@ustb.edu.cn

Received 21 July 2017; Revised 28 October 2017; Accepted 27 November 2017; Published 8 February 2018

Academic Editor: Rishi Gupta

Copyright ( 92018 Qingwen Li et al. This is an open access article distributed under the Creative Commons Attribution License, which permits unrestricted use, distribution, and reproduction in any medium, provided the original work is properly cited.

The latest research on energy piles demonstrates that most scholars are focusing their attention on optimization by designing more efficient heat exchanger coils, analyzing the heat pump matching parameters, and so on. However, after more than 20 years of development, these traditional methods for improving the heat transfer efficiency of energy piles have reached a bottleneck, and a new approach for the continued enhancement of this technology must be investigated. In this study, powdered graphite with high heat transfer characteristics was included in a concrete mix to create graphite concrete piles with enhanced heat transfer characteristics. The results from theoretical analysis, laboratory testing, and numerical simulation indicate that using graphite to improve the heat transfer efficiency of a concrete material is an effective method for enhancing the thermal efficiency of an energy pile system. The research results also show that the heat transfer coefficient of the concrete exhibits greater improvement when the graphite content is greater than $15 \%$ under the same environmental temperature. After studying the performance of the proposed graphite concrete energy pile under different environmental temperatures $\left(10^{\circ} \mathrm{C}, 20^{\circ} \mathrm{C}, 30^{\circ} \mathrm{C}\right.$, and $\left.40^{\circ} \mathrm{C}\right)$, the results indicate that the working efficiency of the energy pile is better in the summer than in the winter. Finally, parameters such as the cast-in pipe configuration and pile spacing are optimized.

\section{Introduction}

With the rapid consumption of coal, petroleum, natural gas, and other nonrenewable resources, energy crisis is always a looming problem for many countries around the world. Energy pile is a clean energy system that utilizes nearly constant geothermal resources to heat or cool buildings. Because of its many advantages, in the past 20 years, the energy pile has seen rapid development around the world and has been well adapted to various energy saving buildings in China, Canada, Japan, and many European countries, among others. Many scholars have studied the heat transfer characteristics of energy piles. To determine the effect of different heat source parameters such as size and structure on the effectiveness of the heat exchange system, Gao et al. studied the thermal performance and ground temperature of vertical pile-foundation heat exchangers and proposed guidelines for better design of large-scale ground-coupled heat pumps in district heating and cooling systems [1]; Moon and Choi researched the heating performance characteristics of a ground source heat pump system with energy piles and energy slabs [2]; heat transfer enhancement mechanisms for geothermal energy piles were investigated by Faizal et al. [3]; Caulk et al. obtained the operating parameters of a calibrated geothermal energy pile model [4]; and Ghasemi-Fare and Basu provided a predictive assessment of the heat exchange performance of geothermal piles [5]. Research has also been conducted on the coil-types of heat exchangers: Cui et al. analyzed the heat transfer characteristics of pile-based geothermal heat exchangers with spiral coils [6]; Go et al. designed a spiral coil PHC energy pile by considering the effective thermal resistance of the borehole as well as groundwater advection effects [7]; Xiang et al. developed a new practical numerical model to simulate an energy pile with spiral coils [8] while Fadejev and Kurnitski used a whole-building simulation to model 
the performance of geothermal energy piles and optimize borehole design when using a heat pump [9]; Park et al. studied a coil-type ground heat exchanger by considering the relative constructability and thermal performance of cast-inplace concrete energy piles [10]; Park et al. calculated the influence of coil pitch on the thermal performance of coiltype cast-in-place energy piles [11]; and Yang et al. conducted laboratory investigations to analyze the thermal performance of an energy pile with a spiral coil ground heat exchanger [12]. Some scholars have conducted research on the heat exchange efficiency of energy piles, including Bozis et al., who evaluated the effects of varying design parameters on the heat transfer efficiency of energy piles [13]; Park et al. estimated the constructability and heat exchange efficiency of large diameter cast-in-place energy piles with various heat exchange pipe configurations [14]; Yoon et al. obtained the thermal efficiency and conducted a cost analysis for different types of ground heat exchangers in energy piles [15]; Cecinato and Loveridge analyzed the influence of energy pile thermal efficiency on system performance [16]; Astrain et al. undertook a comparative study of different heat exchange systems in a thermoelectric refrigerator and their influence on its efficiency [17]; and Akrouch et al. conducted an experimental, analytical, and numerical study on the thermal efficiency of energy piles in unsaturated soils [18]. There has also been research into providing technical guidance for the design and construction of energy piles $[19,20]$.

Clearly, a considerable amount of research has been conducted on energy piles, yielding plentiful and substantial achievements on the optimization of pile parameters, heat exchanger coil types and design, and heat pump matching parameter analysis, among others, in the past 20 years. And now, these approaches to improving efficiency and optimizing heat exchangers are difficult to improve upon. Therefore, a new approach should be proposed to improve heat exchange efficiency continually. In recent years, it would be nice to cite research that have incorporated superplasticizers, fly ash, furnace powder, silicon ash, etc. in concrete material for improving mechanical, construction, and durability properties. Various new types of concrete, such as strong concrete, high-performance concrete, selfcompacting concrete, and reactive powder concrete, have been developed and applied to engineering design problems [21-25]. When considering the thermodynamic properties of concrete, which is mainly a concern in building construction, the use of traditional concrete has placed an emphasis on heat resistance in order to reduce the thermal conductivity coefficient of this primary material. The thermal conductivity coefficient of typical concrete is $1.0-1.5 \mathrm{~W} / \mathrm{mK}$, and the thermal conductivity coefficient of some types of multipore lightweight concrete can be as low as $0.5-1.0 \mathrm{~W} / \mathrm{mK}[26,27]$. Considerable research has shown that different admixtures, aggregates, and material mix proportions, among other parameters, can change the thermal conductivity of concrete [28-32].

In accordance with the findings of previous research into the thermal conductivity of concrete, a strategy to improve

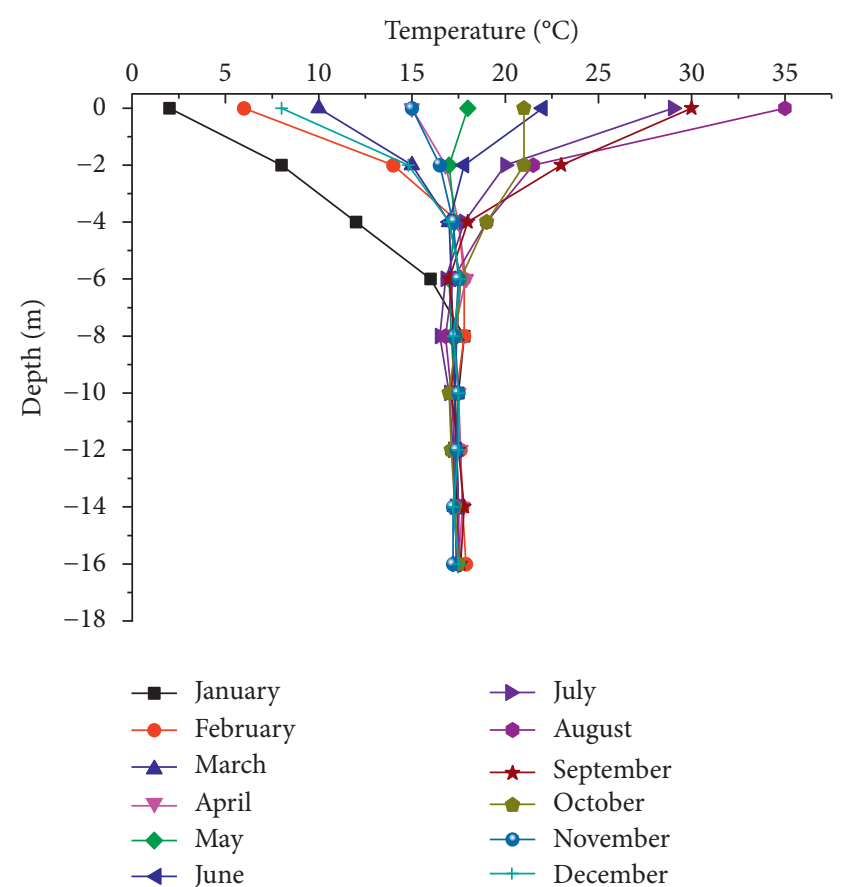

Figure 1: Change in soil temperature with the depth.

the heat transfer characteristics of concrete energy piles by including powdered graphite in the concrete mix is evaluated in this study. First, the effects of different graphite content and different working temperature on the heat transfer characteristics of the concrete are determined by using a heat conductivity coefficient tester. Then, the heat transfer efficiency is calculated with consideration of the cast-in pipe configuration and spacing of the energy piles. The results of the theoretical analysis, laboratory testing, and numerical simulation demonstrate that this new method, which relies on improving the heat transfer efficiency of the concrete, is effective for enhancing the working efficiency of energy pile systems.

\section{Working Mechanism of Energy Pile}

2.1. Ground Temperature Change at Shallow Depths. Energy pile systems take advantage of the stable thermal properties of shallow geothermal resources by exchanging building energy with geothermal energy in the host soil in both summer and winter using underground heat exchanger pipes. The change in superficial soil temperature with depth in Beijing area is shown in Figure 1, where it can be seen that the soil temperature is fairly stable year-round at depths as shallow as $6 \mathrm{~m}$. Indeed, the temperature of soil is much more stable than that of air and has little correlation with environmental changes throughout the year. In the summer, the temperature of the host soil is lower than the temperature of the air; therefore, the host soil acts as a heat sink, providing a lower condensing temperature and increasing refrigeration capacity as the energy pile transfers heat from the building into the ground. In the winter, the temperature of the host soil is higher than the temperature of the air; 


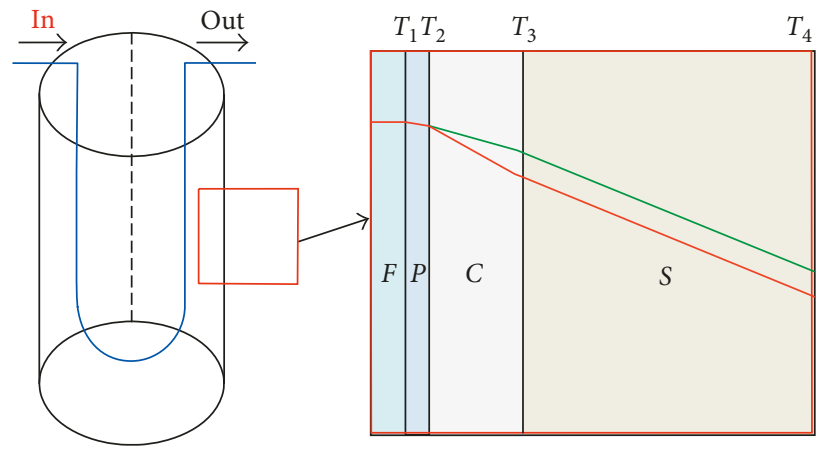

FIGURE 2: Heat transfer schematic of energy pile and heat transfer curves for original (red) and enhanced (green) concrete heat transfer (in summer).

therefore, the soil acts as a heat source, providing a higher evaporating temperature as the energy pile absorbs much more heat than the air and transfers it from the soil into the building.

2.2. Heat Transfer Mechanism of Energy Pile. Typically, energy pile systems comprise an exchange fluid (F), metal pipe $(\mathrm{P})$, concrete pile $(\mathrm{C})$, and host soil (S), as shown in the structural diagram in Figure 2(a). It is well known that thinner metal materials usually exhibit better thermal transmissivity, meaning that there is little heat attenuation across the walls of a metal pipe; thus, its thermal resistance can be ignored. The only media between the exchange fluid and host soil are the metal pipe and concrete, leaving the concrete as the only medium that can produce the desired heat transfer effect. Therefore, by enhancing the heat transfer properties of the concrete, the heat transfer efficiency of the entire energy pile system could be improved, as demonstrated by the change between the original (red curve) and enhanced (green curve) heat transfer curves drawn in Figure 2(b).

In the interest of accurately expressing the thermophysical parameters of the different components in the energy pile system, the concept of thermal resistance is used, meaning that the heat transfer between the exchange fluid and the host soil can be calculated by

$$
\mathrm{Q}=\frac{T_{1}-T_{4}}{R_{T}},
$$

where $Q$ is the heat transfer value, $T_{1}$ is the temperature of the exchange fluid, $T_{4}$ is the temperature of the far field soil, and $R_{T}$ is the total thermal resistance of the energy pile system. To define different materials with different thermal resistances, the total thermal resistance can be divided into

$$
R_{T}=R_{F}+R_{P}+R_{C}+R_{S},
$$

where $R_{F}, R_{P}, R_{C}$, and $R_{S}$ are the thermal resistances of the exchange fluid, metal pipe, concrete, and host soil, respectively. The thermal resistance of each component can be calculated by

$$
\begin{aligned}
& R_{F}=\frac{1}{2 n \pi r_{i} h}, \\
& R_{P}=\frac{\ln \left(r_{o} / r_{i}\right)}{2 n \pi k_{p}}, \\
& R_{C}=\frac{\ln \left(r_{a} / r_{\mathrm{ep}}\right)}{2 \pi k_{c}}, \\
& R_{S}=\frac{\ln \left(r_{s} / r_{p}\right)}{2 \pi k_{s}},
\end{aligned}
$$

where, $r_{i}, r_{o}, r_{a}$, and $r_{p}$ are the inside radius of the metal pipe, the outside radius of the metal pipe, the distance between the metal pipe and the soil, and the radius of the energy pile, respectively. $r_{\text {ep }}=r_{o} \sqrt{n}$, where $n$ is the number of metal pipes and $h$ is the convective heat transfer coefficient. $k_{p}, k_{c}$, and $k_{s}$ are the heat conductivity coefficients of metal pipe, concrete, and host soil, respectively.

\section{Heat Transfer Characteristic Tests of Graphite Concrete}

The analysis in Section 2 demonstrates that the enhancement of the heat transfer characteristics of the concrete is a key objective for improving the heat transfer performance of a concrete energy pile system. In order to realize this enhancement, graphite was selected as a concrete additive as it has little effect on concrete hydration. Due to its special molecular structure, graphite also has a high thermal conductivity in the range of $100-120 \mathrm{~W} / \mathrm{mK}$, which is higher than iron, lead, and other metal materials, and chemical stability that allows it to endure acid, alkaline, and organic solvent corrosion. In order to achieve and verify the enhanced heat transfer of graphite concrete, specific test objectives and detailed testing scheme should be developed.

\subsection{Testing Objectives}

(1) Create mixes of enhanced heat transfer graphite concrete with different volumetric contents of powdered graphite. 
TABLE 1: Composition of graphite concretes.

\begin{tabular}{lccccc}
\hline Volumetric content & Cement $(\mathrm{g})$ & Sand $(\mathrm{g})$ & Water $(\mathrm{g})$ & Water-reducing agent $(\mathrm{g})$ & Powdered graphite $(\mathrm{g})$ \\
\hline Normal concrete & 197 & 799 & 171 & 8.56 & 0 \\
CG5\% & 197 & 799 & 185 & 8.56 & 30 \\
CG10\% & 197 & 799 & 199 & 8.56 & 60 \\
CG15\% & 197 & 799 & 212 & 8.56 & 90 \\
CG25\% & 197 & 799 & 240 & 8.56 & 150 \\
\hline
\end{tabular}

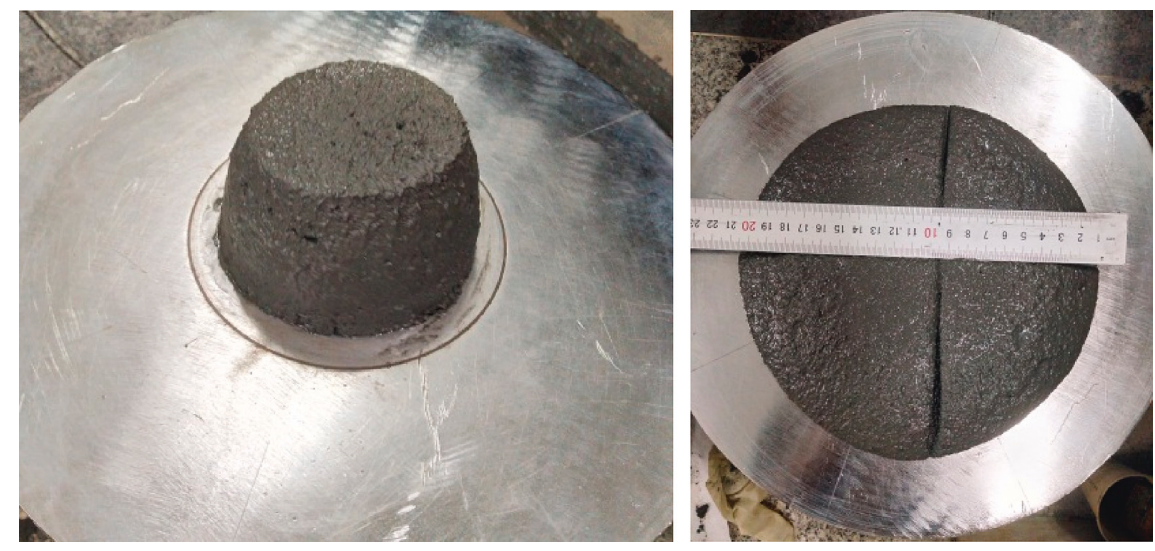

FIgURE 3: Fluidity test of graphite concrete.

(2) Using the results of tests conducted on the graphite concrete, obtain the relationship between the heat conductivity coefficient of graphite concrete and the portion of graphite it contains.

(3) Based on precast graphite concrete samples, determine the temperature effect in summer or winter to obtain the relationship between the heat conductivity coefficient of graphite concrete and various environmental temperatures.

3.2. Testing Scheme. A series of graphite concretes were mixed using cement, sand, water, water-reducing agent, and different volumetric contents of powdered graphite $(0 \%$, $5 \%, 10 \%, 15 \%$, and $25 \%$ ) to confirm heat transfer characteristics on the effects of different addition of graphite. The weight proportions of the different mixes are shown in Table 1. Graphite powder has been observed to contribute to a water absorption effect, and absorbed water cannot contribute to the hydration reaction, instead volatilizing during the curing of specimens and different ratios of the reacting water to the binder can influence the allowable quantity of powdered graphite in the mix. After trial and error, the optimal water content for different graphite contents was selected as shown in Table 1. A horizontal forced mixer was used to stir the mix materials for $2 \mathrm{~min}$. After testing, the slumps of the prepared graphite concretes were 180-200 mm (as shown in Figure 3), and the water retention and cohesion of the concrete were both acceptable. Next, $100 \mathrm{~mm}$ cubic molds were filled with the stirred mixes and placed on a vibrostand to vibrate for 1-2 min. The graphite concrete blocks were then allowed to cure for 28 days before being processed with a drying treatment for 2 days under $80^{\circ} \mathrm{C}$ heat in a drying cabinet. In order to ensure the accuracy of the tests, each concrete block was core-drilled to form 4 test specimens, $50 \mathrm{~mm}$ in diameter and $30 \mathrm{~mm}$ high, as shown in Figure 4 .

The heat conductivity test was conducted using a DREIII heat conductivity coefficient tester. The measuring probe of this instrument is made of metallic nickel with $10 \Omega$ resistance, its measurable temperature is in the range of $-50^{\circ} \mathrm{C}$ to $150^{\circ} \mathrm{C}$, and its thickness is $0.16 \pm 0.02 \mathrm{~mm}$. The measuring probe, testing instrument, and test setup are shown in Figure 5.

3.3. Test Result Analysis. An energy pile system usually works through the entire summer and winter, so the environmental temperature has an important influence on heat transfer. In the interest of determining the different temperature effects of summer and winter, the stipulations in "Technical code for ground-source heat pump system, 2009, China" [33] were used to structure the analysis. The code states that in the summer, the working temperature at the water outlet of the heat exchanger pipe should not exceed $33^{\circ} \mathrm{C}$, and the temperature at the entrance must be a little higher than at the outlet. Accordingly, four temperature levels, $10^{\circ} \mathrm{C}, 20^{\circ} \mathrm{C}, 30^{\circ} \mathrm{C}$, and $40^{\circ} \mathrm{C}$, were set as the target environmental temperatures. Typical infrared images of graphite concrete under these different environmental temperatures are shown in Figure 6. There are four thermal conditions to test for each of the five different mixes, and each of the four samples cut from a single block is tested under different temperatures. After testing the heat 


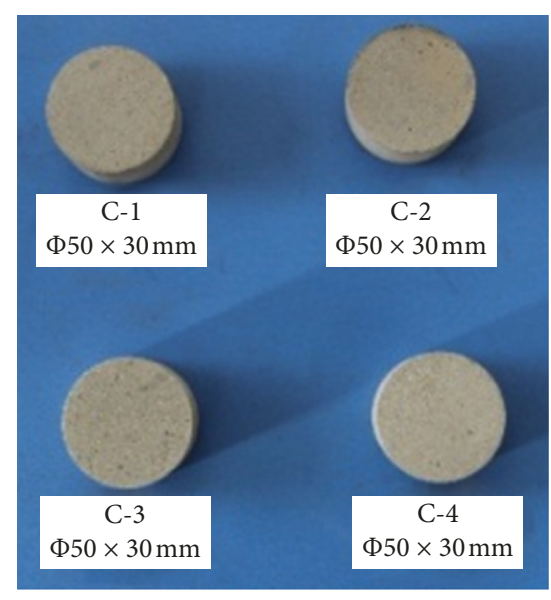

(a)

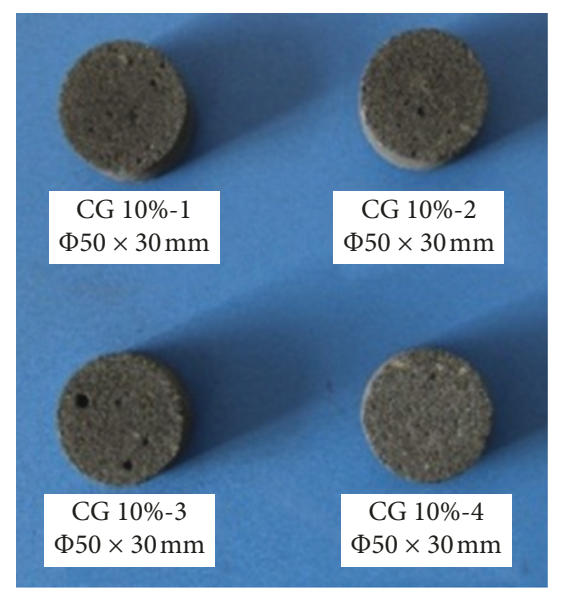

(c)

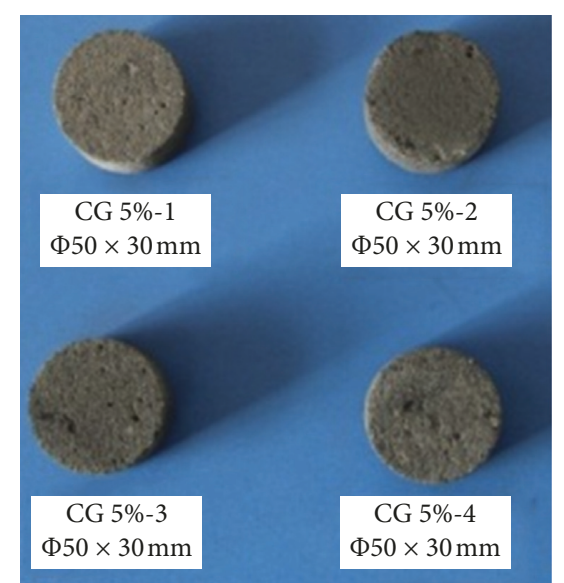

(b)

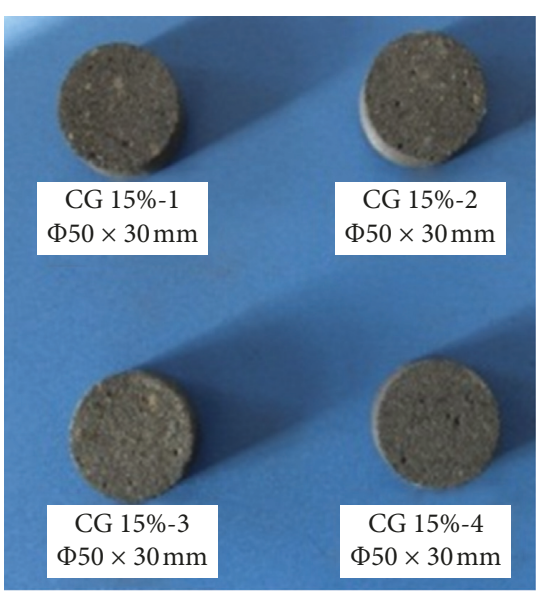

(d)

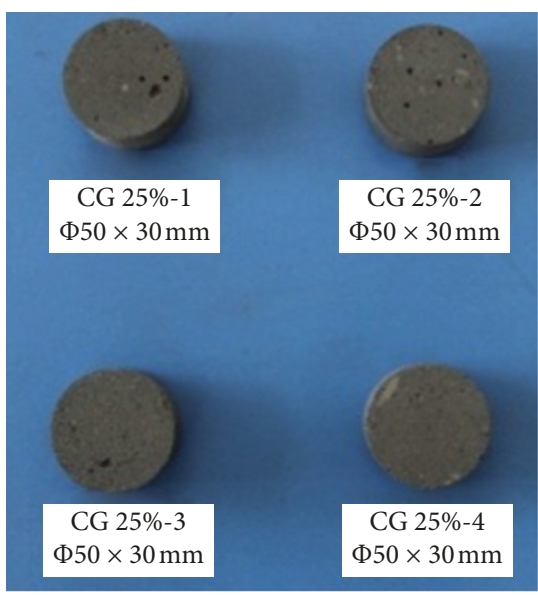

(e)

Figure 4: Concrete specimens with different graphite contents. (a) $0 \%$. (b) 5\%. (c) $10 \%$. (d) $15 \%$. (e) $25 \%$.

conductivity of concrete with $0 \%, 5 \%, 10 \%, 15 \%$, and $25 \%$ graphite volumetric content, each under environmental temperatures of $10^{\circ} \mathrm{C}, 20^{\circ} \mathrm{C}, 30^{\circ} \mathrm{C}$, and $40^{\circ} \mathrm{C}$, the average results are provided in Table 2.
As shown in Table 2, the highest heat conductivity coefficient is $2.84 \mathrm{~W} / \mathrm{mK}$ for the $25 \%$ graphite volumetric content at $40^{\circ} \mathrm{C}$, which is about 2 times that of the normal concrete at $1.0-1.5 \mathrm{~W} / \mathrm{mK}$, or 3-6 times that of some 

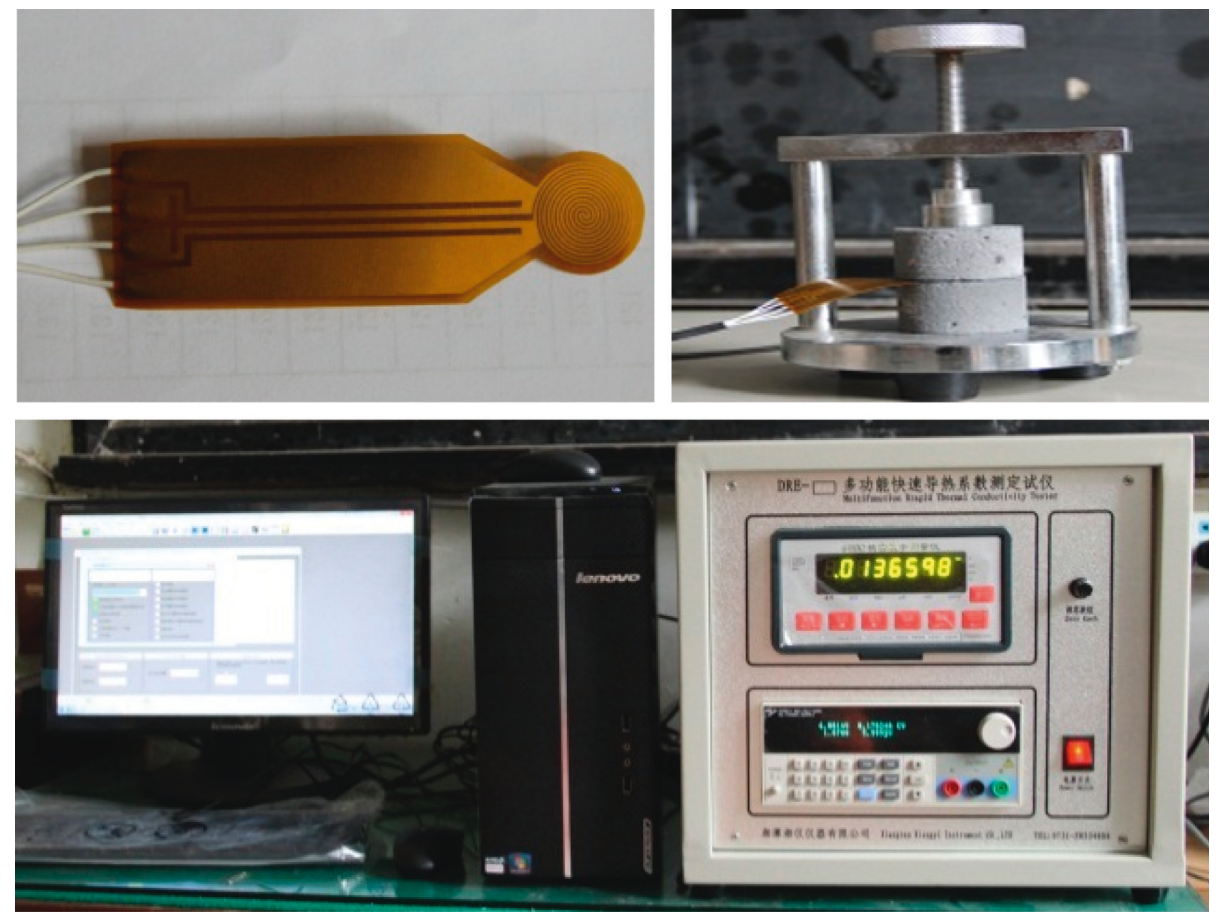

FIGURE 5: DRE-III heat conductivity coefficient tester and the test setup.

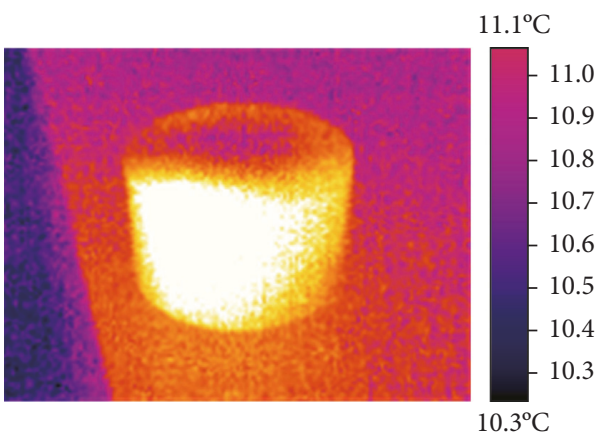

(a)

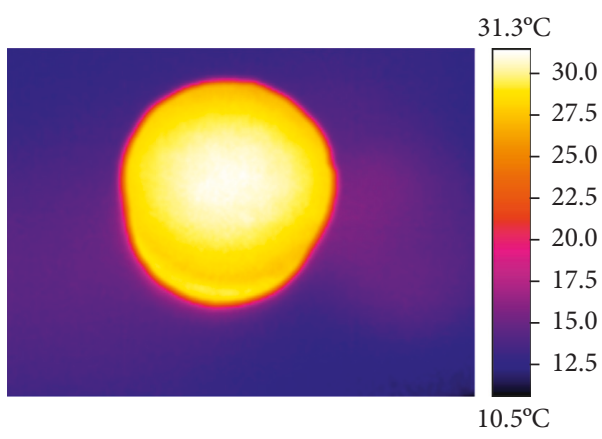

(c)

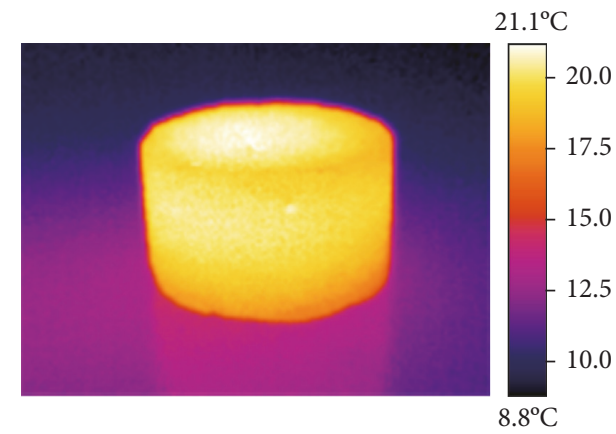

(b)

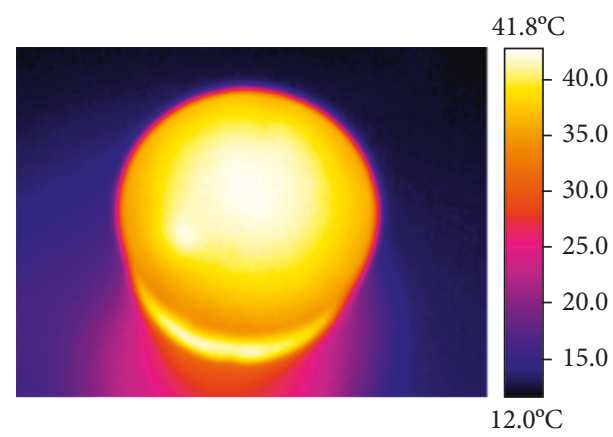

(d)

FIgURE 6: Infrared pictures of graphite concrete under different environmental temperatures. (a) $10^{\circ} \mathrm{C}$. (b) $20^{\circ} \mathrm{C}$. (c) $30^{\circ} \mathrm{C}$. (d) $40^{\circ} \mathrm{C}$.

multipore lightweight concretes [26, 27]. Meanwhile, the fitted curves for the heat conductivity coefficients under different graphite contents and different environmental temperatures are shown in Figures 7(a) and 7(b), respectively.
By adopting polynomial fitted formulae, the fitted formulae were obtained from Figures 7 (a) and (b), yielding the heat conductivity coefficients for different graphite contents shown in 
TABLE 2: Heat conductivity coefficient test results (W/mK).

\begin{tabular}{lccccc}
\hline Environmental temperature & 0\% graphite & $5 \%$ graphite & $10 \%$ graphite & 15\% graphite & $25 \%$ graphite \\
\hline $10^{\circ} \mathrm{C}$ & 1.38 & 1.30 & 1.33 & 1.63 & 2.05 \\
$20^{\circ} \mathrm{C}$ & 1.43 & 1.40 & 1.48 & 1.67 & 2.12 \\
$30^{\circ} \mathrm{C}$ & 1.60 & 1.51 & 1.52 & 1.74 & 2.39 \\
$40^{\circ} \mathrm{C}$ & 1.71 & 1.62 & 1.76 & 2.84 \\
\hline
\end{tabular}

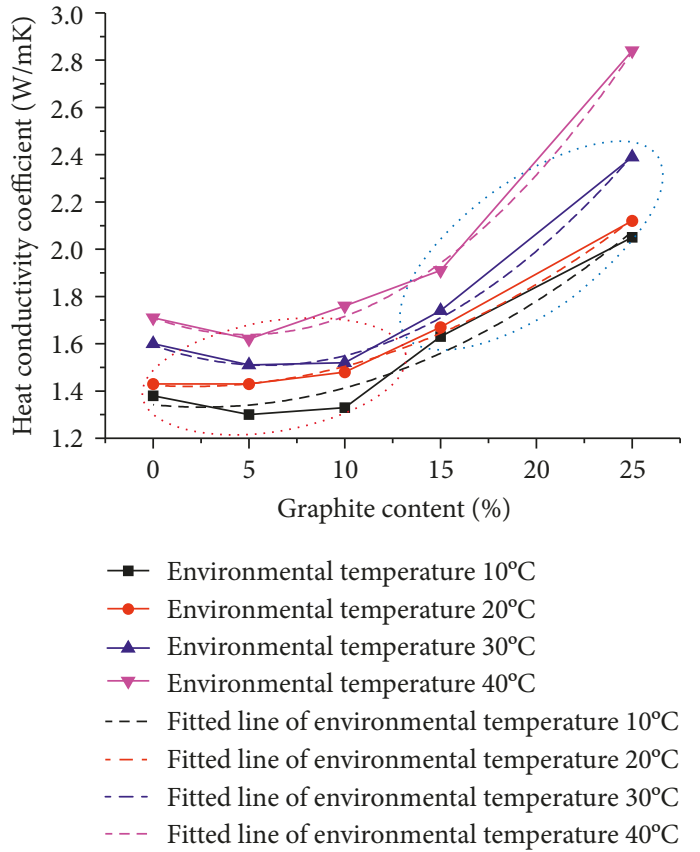

(a)

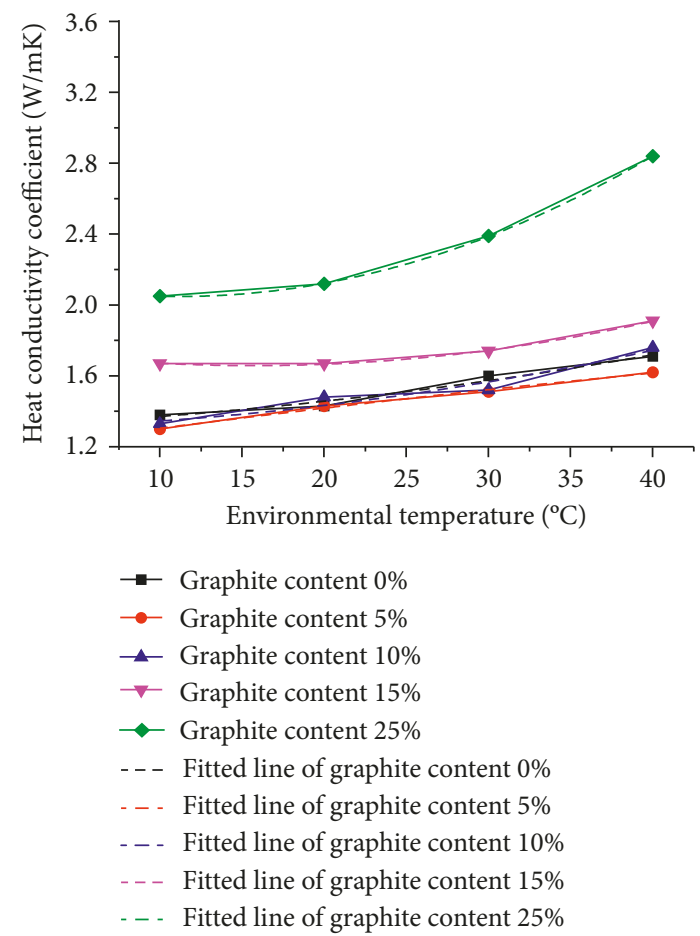

(b)

Figure 7: Heat conductivity coefficients of tested graphite concretes. (a) Different graphite contents. (b) Different environmental temperatures.

$$
\begin{aligned}
& k_{c 10^{\circ} \mathrm{C}}=1.342-0.0076 C+0.00148 C^{2} \\
& k_{c 20^{\circ} \mathrm{C}}=1.424-0.00534 C+0.00133 C^{2} \\
& k_{c 30^{\circ} \mathrm{C}}=1.594-0.0288 C+0.00243 C^{2} \\
& k_{c 40^{\circ} \mathrm{C}}=1.709-0.0288 C+0.00295 C^{2} .
\end{aligned}
$$

The following equation gives the heat conductivity coefficients for different environmental temperatures:

$$
\begin{aligned}
& k_{c 0 \%}=1.315+0.0041 T+1.5 e^{-4} T^{2} \\
& k_{c 5 \%}=1.18+0.0129 T-5 e^{-5} T^{2} \\
& k_{c 10 \%}=1.303+0.0021 T+2.25 e^{-4} T^{2} \\
& k_{c 15 \%}=1.76-0.0134 T+4.25 e^{-4} T^{2} \\
& k_{c 25 \%}=2.165-0.021 T+9.5 e^{-4} T^{2} .
\end{aligned}
$$

As shown in Figures 7(a) and 7(b), under the same environmental temperature, the heat conductivity coefficients increase with increasing graphite contents.
Different slopes indicate different growth rates, implying that the gentle slope in the segment of the curves at low graphite contents (below 10\%, highlighted by the red dashed circle) indicates a low enhancement of heat transfer ability. Similarly, the slope in the curve segment above $10 \%$ graphite contents (highlighted by the blue dashed circle) is quite steep, suggesting significantly enhanced heat transfer characteristics. When the graphite volumetric content is $25 \%$, the heat conductivity coefficient of the graphite concrete is almost twice that of the plain cement concrete, demonstrating that the use of graphite concrete can serve as an effective method for improving the heat transfer efficiency of energy pile systems. For concrete with same graphite content, heat conductivity coefficients present a rising trend with the increase in temperature, especially for concrete with high graphite content, suggesting that higher environmental temperatures will lead to improved heat transfer, or, in other words, the energy pile system will work more efficiently in the summer than in the winter. 
TABLE 3: Total thermal resistance for different graphite volumetric contents $\left(\mathrm{mKW}^{-1}\right)$.

\begin{tabular}{lccccc}
\hline Environmental temperature & 0\% graphite & 5\% graphite & 10\% graphite & 15\% graphite & $25 \%$ graphite \\
\hline $10^{\circ} \mathrm{C}$ & 0.444 & 0.458 & 0.453 & 0.409 & 0.370 \\
$20^{\circ} \mathrm{C}$ & 0.436 & 0.441 & 0.429 & 0.405 & 0.365 \\
$30^{\circ} \mathrm{C}$ & 0.413 & 0.425 & 0.423 & 0.397 \\
$40^{\circ} \mathrm{C}$ & 0.401 & 0.411 & 0.395 & 0.381 & 0.349 \\
\hline
\end{tabular}

\section{Effect of Different Factors on the Graphite Concrete Energy Pile}

4.1. Total Thermal Resistance Analysis. By inserting (3) into (2), and ignoring the thermal resistance of the exchange liquid, the total thermal resistance of the energy pile can be expressed as

$$
R_{T}=R_{P}+R_{C}+R_{S}
$$

In order to conduct an analysis, some dimensional information was taken from an in situ energy pile. The subject pile has a radius $r_{p}$ of $400 \mathrm{~mm}$; the outside radius of the metal pipe $r_{o}$ is $10 \mathrm{~mm}$ and its inside radius $r_{i}$ is $8 \mathrm{~mm}$; there are $n=2$ for $\mathrm{U}$-shaped pipes cast in the pile with an equivalent radius $r_{\mathrm{ep}}=1.5 \sqrt{2} \mathrm{~mm}$ and $r_{a}=100 \mathrm{~mm}$; the pile spacing is $3 r_{p}$; and the heat conductivity coefficient of the soil is $0.8 \mathrm{~W} / \mathrm{mK}$. Solving (6) using the heat conductivity coefficients of graphite concrete shown in Table 2 and these dimensions, by the same method of detail calculation example in Appendix A, the total thermal resistance of the energy pile system obtained for different graphite contents is shown in Table 3 and Figure 8, where it can be seen that the total thermal resistance of the energy pile system decreased with the increase in graphite content under the same environmental temperature. The smallest thermal resistance is $0.212 \mathrm{mKW}^{-1}$ for $25 \%$ graphite content.

4.2. Comparative Analysis of Pipe Configuration. In order to determine the effect of graphite contents on the thermal performance of different pipe configurations (as shown in Figure 9), U-shaped, double U-shaped, and W-shaped pipe configurations were evaluated under the summer working condition $\left(40^{\circ} \mathrm{C}\right.$ environmental temperature). For use in (3), the number of pipes $n$ was taken as 2,4 , and 4 , for $U$-shaped, double U-shaped, and $\mathrm{W}$-shaped pipes, respectively. Additionally, note that the distance between the pipe and host soil, $r_{a}$, is different for double U-shaped $(100 \mathrm{~mm})$ and $\mathrm{W}$-shaped $(110 \mathrm{~mm})$ configurations. Adopting the same method of detail calculation example in Appendix B, the resulting curves for the thermal resistance of different pipe configurations are as shown in Table 4 and Figure 10.

From Figure 10, it can be seen that the total thermal resistance of the double U-shaped configuration is the lowest, meaning that this configuration has the highest heat transfer efficiency. Notably, the thermal resistance of the U-shaped pipe configuration decreases the fastest with the increase in graphite contents, demonstrating that thermal enhancement effect of the graphite concrete will be more beneficial to fewer pipes in the system.

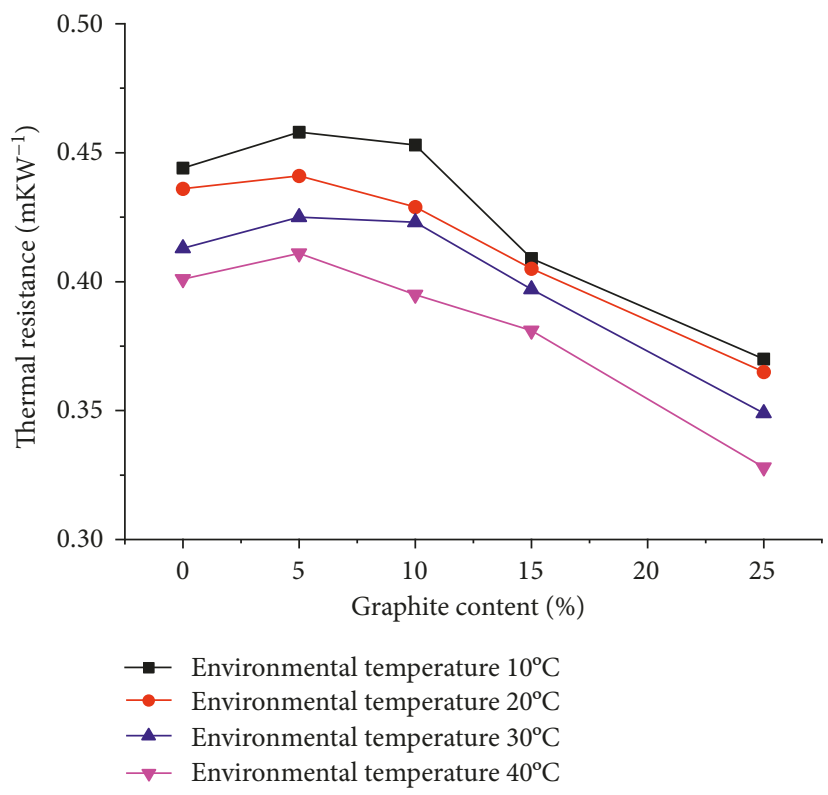

FIgURE 8: Thermal resistance of energy pile system for different graphite volumetric contents.

4.3. Numerical Verification of Heat Transfer. In order to confirm the calculated enhancement to heat transfer behavior resulting from the use of graphite concrete, the numerical software package COMSOL Multiphysics was used to simulate the heat transfer behavior of an energy pile with a U-shaped cast-in pipe under summer working conditions. The resulting contour predictions for different graphite contents are shown in Figure 11.

By analyzing the predicted contours in Figure 11, it is clear that the boundary temperature with the increase in graphite content verifies the ability of concrete with higher graphite contents to provide enhanced heat transfer efficiency. Due to the process of heat attenuation, the temperature at the entrance can be observed to be higher than that at exit. By comparing the distribution of isothermal lines in Figure 11 across the different levels of graphite contents, a tighter, more even distribution of isothermal lines can be seen for energy piles with higher graphite contents, suggesting, again, an enhancement to the heat transfer process.

\section{Conclusions}

(1) Because of the superior heat conductivity and chemical characteristics of graphite, powdered graphite was selected to serve as a concrete additive 


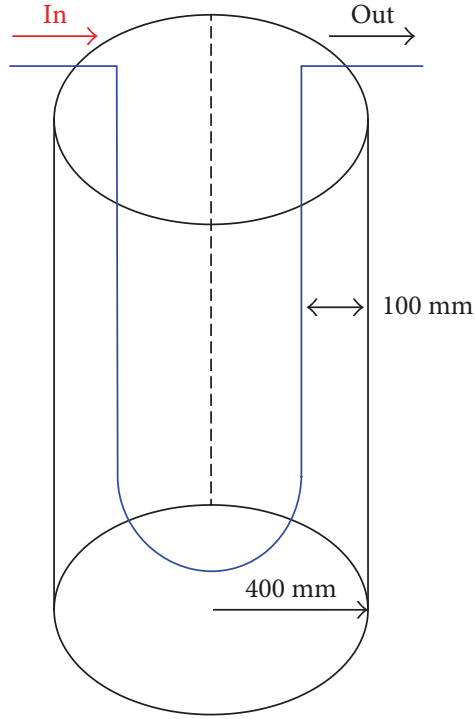

(a)

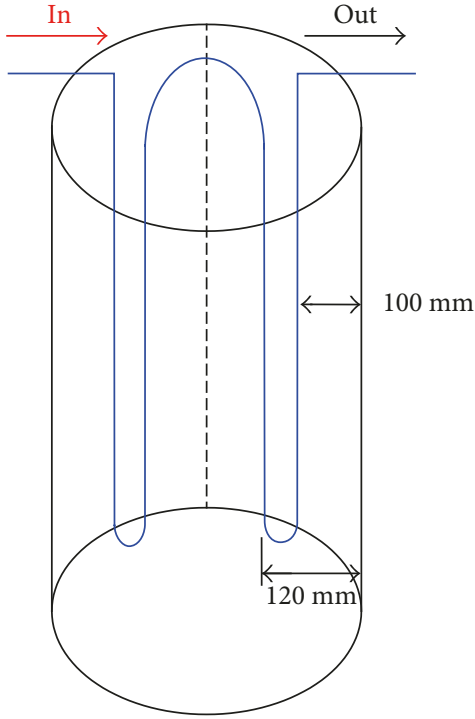

(b)

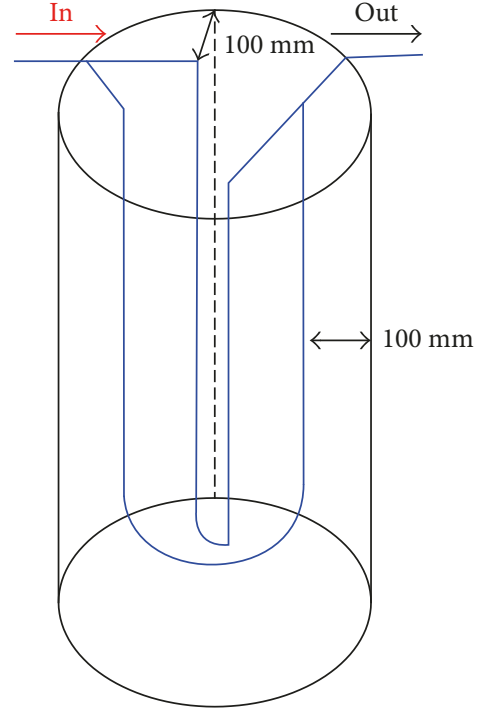

(c)

FIGURE 9: Different pipe configurations cast-in pile. (a) U-shaped. (b) W-shaped. (c) Double U-shaped.

TABLE 4: Total thermal resistance for different pipe configurations $\left(\mathrm{mKW}^{-1}\right)$.

\begin{tabular}{|c|c|c|c|c|c|}
\hline Environmental temperature & $0 \%$ graphite & $5 \%$ graphite & $10 \%$ graphite & 15\% graphite & $25 \%$ graphite \\
\hline U shape & 0.401 & 0.411 & 0.395 & 0.381 & 0.328 \\
\hline W shape & 0.377 & 0.386 & 0.372 & 0.360 & 0.314 \\
\hline Double U shape & 0.368 & 0.376 & 0.364 & 0.352 & 0.308 \\
\hline
\end{tabular}

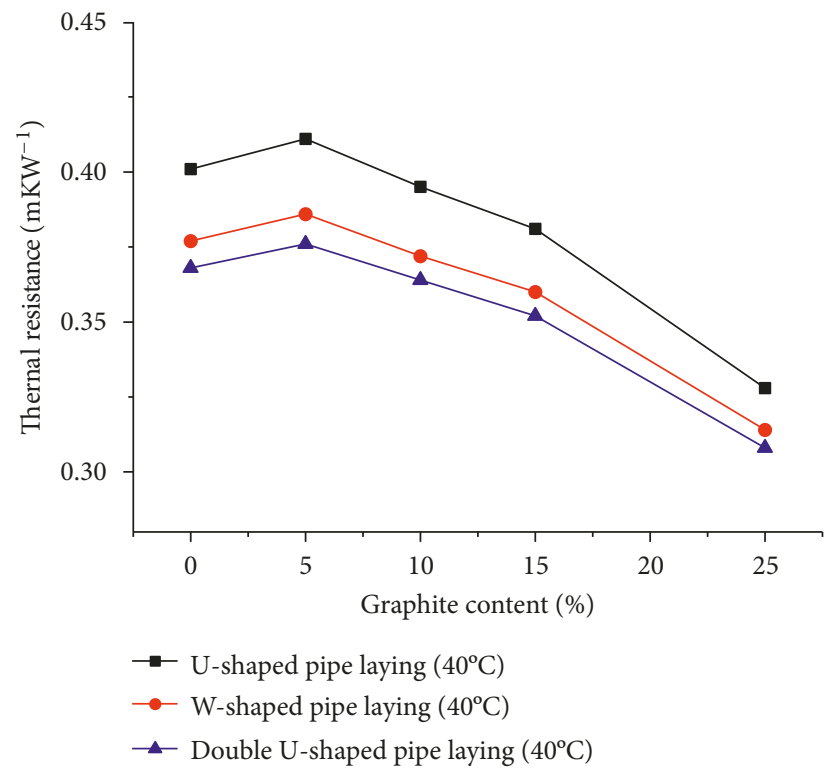

Figure 10: Thermal resistance of an energy pile for different pipe configurations. 


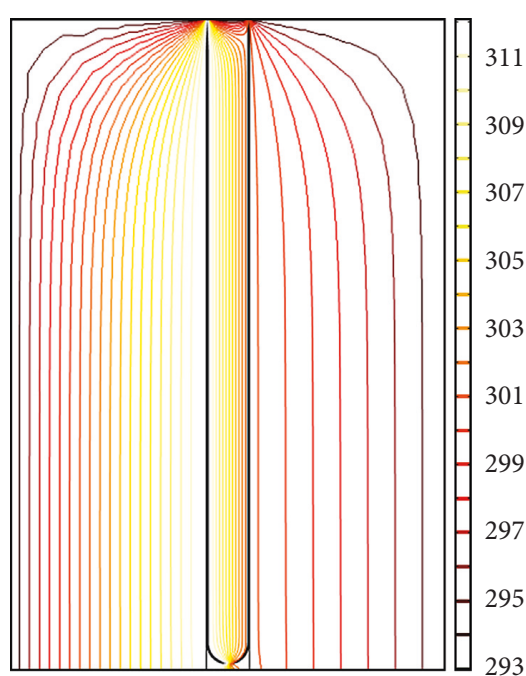

(a)

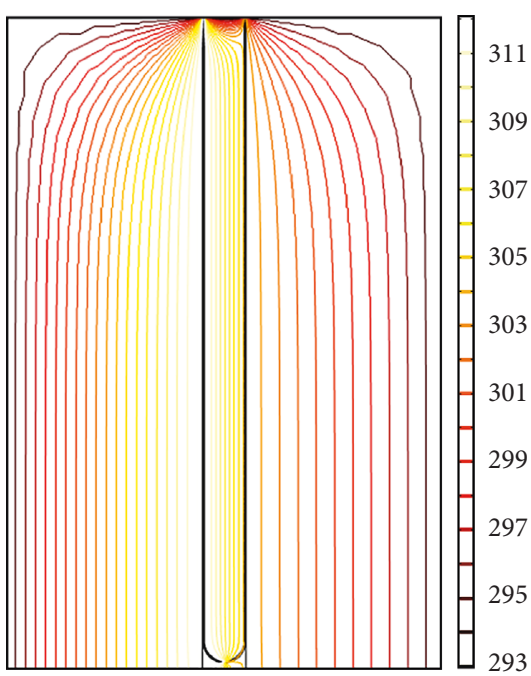

(c)

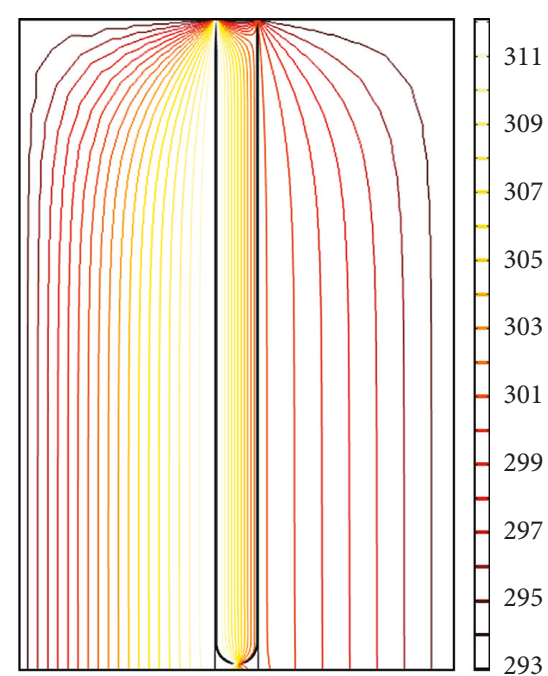

(b)

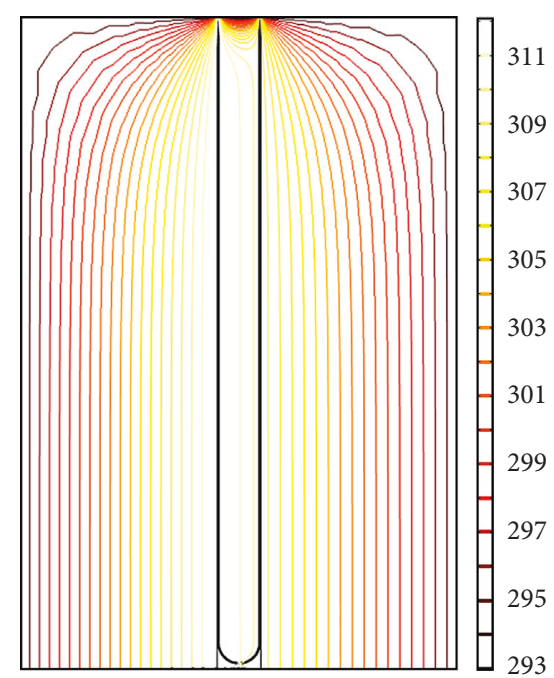

(d)

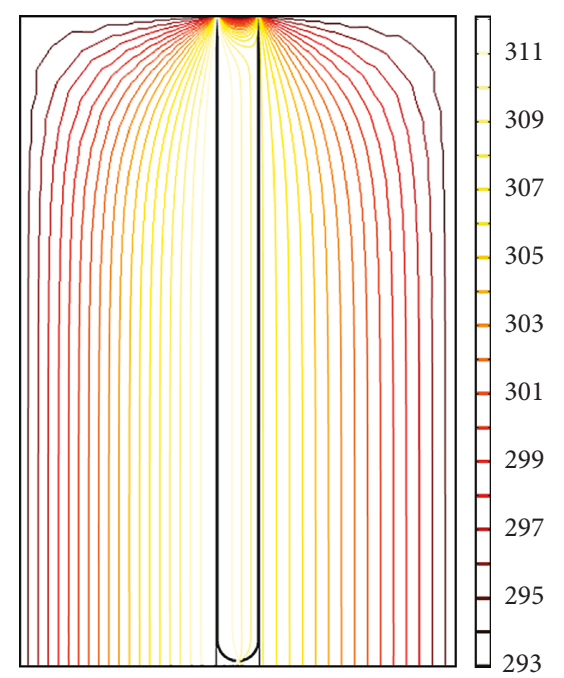

(e)

FiguRE 11: Predicted contours for heat transfer in energy piles with different graphite volumetric contents. (a) $0 \%$. (b) $5 \%$. (c) $10 \%$. (d) $15 \%$. (e) $25 \%$. 
to enhance the heat transfer properties of concrete used in energy piles. Testing specimens were drilled from cast concrete blocks with different graphite contents $(0 \%, 5 \%, 10 \%, 15 \%$, and $25 \%)$.

(2) Using a DRE-III heat conductivity coefficient tester to determine the heat conductivity of the samples, the heat conductivity coefficients of concretes with different graphite contents at different environmental temperatures $\left(10^{\circ} \mathrm{C}, 20^{\circ} \mathrm{C}, 30^{\circ} \mathrm{C}\right.$, and $\left.40^{\circ} \mathrm{C}\right)$ were calculated. The results indicate that the addition of graphite clearly enhances the heat transfer coefficient, especially for concretes with graphite contents higher than $15 \%$. The results also reveal that a graphite concrete energy pile will work more efficiently in summer than in the winter.

(3) Based on the analysis of the effects of various parameters such as the coil-type of the heat exchanger and the pile spacing, the parameters for optimal heat transfer efficiency were determined. A numerical model then provided results that also verify the ability of graphite concrete to enhance the heat transfer characteristics of energy piles and showed that a higher graphite content is more beneficial to the heat transfer process.

\section{Appendix}

\section{A. Example Calculation for Figure 8 (U-Shaped Pipe Cast-In Pile)}

(1) For the thermal resistance of metal pipe, $r_{i}=8 \mathrm{~mm}$, $r_{o}=10 \mathrm{~mm}, n=2$, and $k_{p}=45$. So,

$R_{P}=\frac{\ln \left(r_{o} / r_{i}\right)}{2 n \pi k_{p}}=\frac{\ln (10 / 8)}{2 \times 2 \times 3.14 \times 45}=0.0004$.

(2) For thermal resistance of graphite concrete, $r_{a}=$ $100 \mathrm{~mm}, r_{\text {ep }}=r_{o} \sqrt{n}=10 \sqrt{2}=14.14$, and $k_{c}=1.38$ $\left(0 \%\right.$ graphite, $\left.10^{\circ} \mathrm{C}\right)$. So,

$$
R_{C}=\frac{\ln \left(r_{a} / r_{e p}\right)}{2 \pi k_{c}}=\frac{\ln (100 / 14.14)}{2 \times 3.14 \times 1.38}=0.226 .
$$

(3) For thermal resistance of host soil, $r_{p}=400 \mathrm{~mm}$, $m=1200 \mathrm{~mm}$, and $k_{s}=0.8$. So,

$$
R_{S}=\frac{\ln 3}{2 \times 3.14 \times 0.8}=0.218 .
$$

(4) Total thermal resistance of energy pile system.

$$
R_{T}=R_{P}+R_{C}+R_{S}=0.0004+0.226+0.218=0.444 .
$$

\section{B. Example Calculation for Figure 10 $\left(40^{\circ} \mathrm{C}\right.$ Environmental Temperature, Double U Shaped)}

(1) For the thermal resistance of metal pipe, $r_{i}=8 \mathrm{~mm}$, $r_{o}=10 \mathrm{~mm}, n=4$, and $k_{p}=45$. So,

$$
R_{P}=\frac{\ln \left(r_{o} / r_{i}\right)}{2 n \pi k_{p}}=\frac{\ln (10 / 8)}{2 \times 4 \times 3.14 \times 45}=0.0002 \text {. }
$$

(2) For thermal resistance of graphite concrete, $r_{a}=100 \mathrm{~mm}, r_{\mathrm{ep}}=r_{o} \sqrt{n}=10 \sqrt{4}=20$, and $k_{c}=1.71$ $\left(0 \%\right.$ graphite, $\left.40^{\circ} \mathrm{C}\right)$. So,

$$
R_{C}=\frac{\ln \left(r_{a} / r_{e p}\right)}{2 \pi k_{c}}=\frac{\ln (100 / 20)}{2 \times 3.14 \times 1.71}=0.150 .
$$

(3) For thermal resistance of host soil, $r_{p}=400 \mathrm{~mm}$, $m=1200 \mathrm{~mm}$, and $k_{s}=0.8$. So,

$$
R_{S}=\frac{\ln 3}{2 \times 3.14 \times 0.8}=0.218 \text {. }
$$

(4) Total thermal resistance of energy pile system.

$$
R_{T}=R_{P}+R_{C}+R_{S}=0.0002+0.150+0.218=0.368 .
$$

\section{Conflicts of Interest}

The authors declare that there are no conflicts of interest regarding the publication of this paper.

\section{Acknowledgments}

This work was supported by the Opening Funds of State Key Laboratory of Building Safety and Built Environment (no. BSBE2015-06) and the Joint Research Program between University of Science and Technology, Beijing, and National Taipei University of Technology (no. TW201703).

\section{References}

[1] J. Gao, X. Zhang, J. Liu, K. S. Li, and J. Yang, "Thermal performance and ground temperature of vertical pile-foundation heat exchangers: a case study," Applied Thermal Engineering, vol. 28, no. 17-18, pp. 2295-2304, 2008.

[2] C.-E. Moon and J. M. Choi, "Heating performance characteristics of the ground source heat pump system with energy-piles and energy-slabs," Energy, vol. 81, pp. 27-32, 2015.

[3] M. Faizal, A. Bouazza, and R. M. Singh, "Heat transfer enhancement of geothermal energy piles," Renewable and Sustainable Energy Reviews, vol. 57, pp. 16-33, 2016. 
[4] R. Caulk, E. Ghazanfari, and J. S. McCartney, "Parameterization of a calibrated geothermal energy pile model," Geomechanics for Energy and the Environment, vol. 5, pp. 1-15, 2016.

[5] O. Ghasemi-Fare and P. Basu, "Predictive assessment of heat exchange performance of geothermal piles," Renewable Energy, vol. 86, pp. 1178-1196, 2016.

[6] P. Cui, X. Li, Y. Man, and Z. Fang, "Heat transfer analysis of pile geothermal heat exchangers with spiral coils," Applied Energy, vol. 88, no. 11, pp. 4113-4119, 2011.

[7] G.-H. Go, S.-R. Lee, S. Yoon, and H.-B. Kang, "Design of spiral coil PHC energy pile considering effective borehole thermal resistance and groundwater advection effects," Applied Energy, vol. 125, pp. 165-178, 2014.

[8] Y. Xiang, H. Su, W. Gou et al., "A new practical numerical model for the energy pile with spiral coils," International Journal of Heat and Mass Transfer, vol. 91, pp. 777-784, 2015.

[9] J. Fadejev and J. Kurnitski, "Geothermal energy piles and boreholes design with heat pump in a whole building simulation software," Energy and Buildings, vol. 106, pp. 23-34, 2015.

[10] S. Park, D. Lee, H.-J. Choi, K. Jung, and H. Choi, "Relative constructability and thermal performance of cast-in-place concrete energy pile: coil-type GHEX (ground heat exchanger)," Energy, vol. 81, pp. 56-66, 2015.

[11] S. Park, S. Lee, D. Lee, S. S. Lee, and H. Choi, "Influence of coil pitch on thermal performance of coil-typecast-in-place energy piles," Energy and Buildings, vol. 129, pp. 344-356, 2016.

[12] W. Yang, P. Lu, and Y. Chen, "Laboratory investigations of the thermal performance of an energypile with spiral coil ground heat exchanger," Energy and Buildings, vol. 128, pp. 491-502, 2016.

[13] D. Bozis, K. Papakostas, and N. Kyriakis, "On the evaluation of design parameters effects on the heat transfer efficiency of energy piles," Energy and Buildings, vol. 43, no. 4, pp. 10201029, 2011.

[14] S. Park, C. Sung, K. Jung, B. Sohn, A. Chauchois, and H. Choi, "Constructability and heat exchange efficiency of large diameter cast-in-place energy piles with various configurations of heat exchange pipe," Applied Thermal Engineering, vol. 90, pp. 1061-1071, 2015.

[15] S. Yoon, S.-R. Lee, J. Xue, K. Zosseder, G.-H. Go, and H. Park, "Evaluation of the thermal efficiency and a cost analysis of different types of ground heat exchangers in energy piles," Energy Conversion and Management, vol. 105, pp. 393-402, 2015.

[16] F. Cecinato and F. A. Loveridge, "Influences on the thermal efficiency of energy piles," Energy, vol. 82, pp. 1021-1033, 2015.

[17] D. Astrain, P. Aranguren, A. Martínez, A. Rodríguez, and M. G. Pérez, "A comparative study of different heat exchange systems in a thermoelectric refrigerator and their influence on the efficiency," Applied Thermal Engineering, vol. 103, pp. 1289-1298, 2016.

[18] G. A. Akrouch, M. Sánchez, and J.-L. Briaud, “An experimental, analytical and numerical study on the thermal efficiency of energy piles in unsaturated soils," Computers and Geotechnics, vol. 71, pp. 207-220, 2016.

[19] Y. Hamada, H. Saitoh, M. Nakamura, H. Kubota, and K. Ochifuji, "Field performance of an energy pile system for space heating," Energy and Buildings, vol. 39, no. 5, pp. 517-524, 2007.

[20] O. Ghasemi-Fare and P. Basu, "A practical heat transfer model for geothermal piles," Energy and Buildings, vol. 66, pp. 470-479, 2013.
[21] C.-H. Huang, S.-K. Lin, C.-S. Chang, and H.-J. Chen, "Mix proportions and mechanical properties of concrete containing very high-volume of Class F fly ash," Construction and Building Materials, vol. 46, pp. 71-78, 2013.

[22] M. Solikin, "Compressive strength development of high strength high volume fly ash concrete by using local material," Materials Science Forum, vol. 872, pp. 271-275, 2016.

[23] P. Hájek, C. Fiala, and A. Lupíšek, "High performance concrete for environmentally efficient building structures," Key Engineering Materials, vol. 691, pp. 272-284, 2016.

[24] S. Asadollahi, A. Saeedian, M. Dehestani, and F. Zahedi, "Improved compressive fracture models for self-consolidating concrete (SCC)," Construction and Building Materials, vol. 123, pp. 473-480, 2016.

[25] S. Ahmad, A. Zubair, and M. Maslehuddin, "Effect of key mixture parameters on flow and mechanical properties of reactive powder concrete," Construction and Building Materials, vol. 99, pp. 73-81, 2015.

[26] S. Real, J. A. Bogas, M. da Gloria Gomes, and B. Ferrer, "Thermal conductivity of structural lightweight aggregate concrete," Magazine of Concrete Research, vol. 68, pp. 798808, 2016.

[27] M. Y. J. Liu, U. J. Alengaram, M. Z. Jumaat, and K. H. Mo, "Evaluation of thermal conductivity, mechanical and transport properties of lightweight aggregate foamed geopolymer concrete," Energy and Buildings, vol. 72, pp. 238-245, 2014.

[28] R. Demirboğa, "Influence of mineral admixtures on thermal conductivity and compressive strength of mortar," Energy and Buildings, vol. 35, no. 2, pp. 189-192, 2003.

[29] J. M. Wong, F. P. Glasser, and M. S. Imbabi, "Evaluation of thermal conductivity in air permeable concrete for dynamic breathing wall construction," Cement \& Concrete Composites, vol. 29, no. 9, pp. 647-655, 2007.

[30] N. Ukrainczyk and T. Matusinović, "Thermal properties of hydrating calcium aluminate cement pastes," Cement and Concrete Research, vol. 40, no. 1, pp. 128-136, 2010.

[31] B. Merckx, P. Dudoignon, J. P. Garnier, and D. Marchand, "Simplified transient hot-wire method for effective thermal conductivity measurement in geomaterials: microstructure and saturation effect," Advances in Civil Engineering, vol. 2012, Article ID 625395, 10 pages, 2012.

[32] L. Shen, Q. Ren, L. Zhang, Y. Han, and G. Cusatis, "Experimental and numerical study of effective thermal conductivity of cracked concrete," Construction and Building Materials, vol. 153, pp. 55-68, 2017.

[33] PRC, M.o.H.a.U.-R.D.o.t., Technical Code for Ground-Source Heat Pump System, China Building Industry Press, Beijing, China, 2009. 


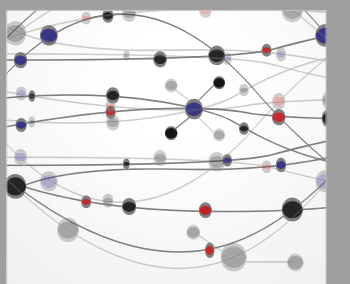

The Scientific World Journal
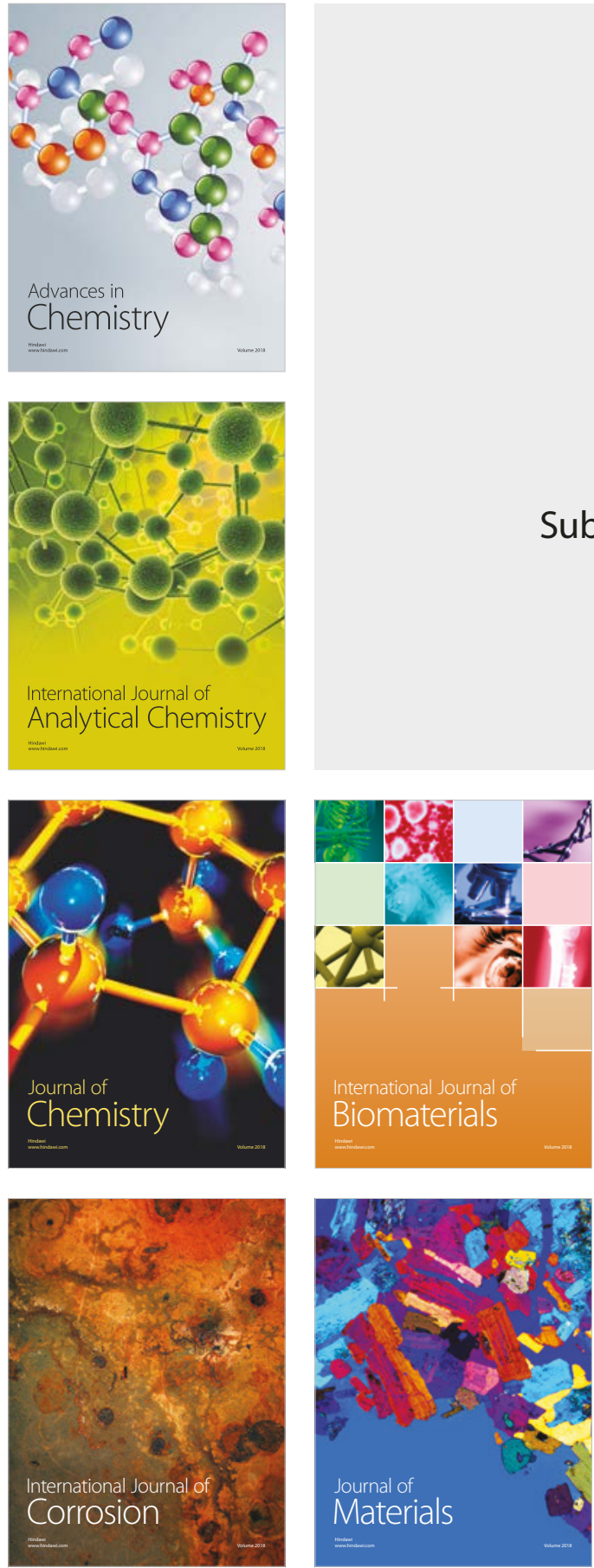

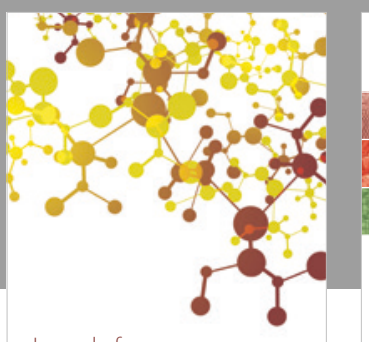

Journal of

Applied Chemistry
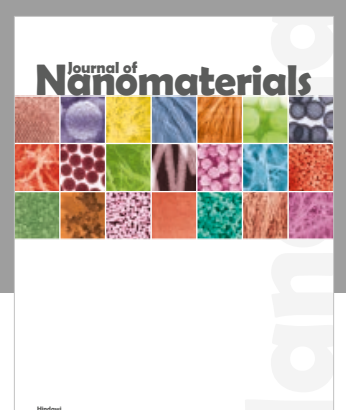

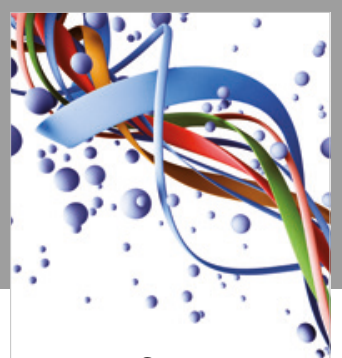

Scientifica

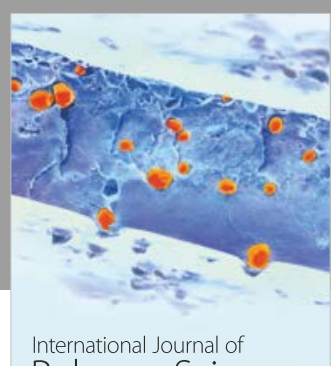

Polymer Science

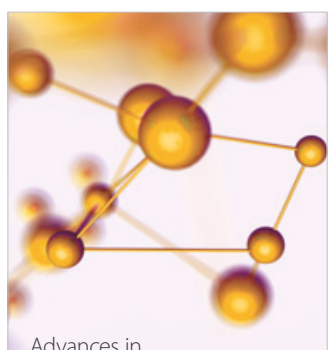

Physical Chemistry
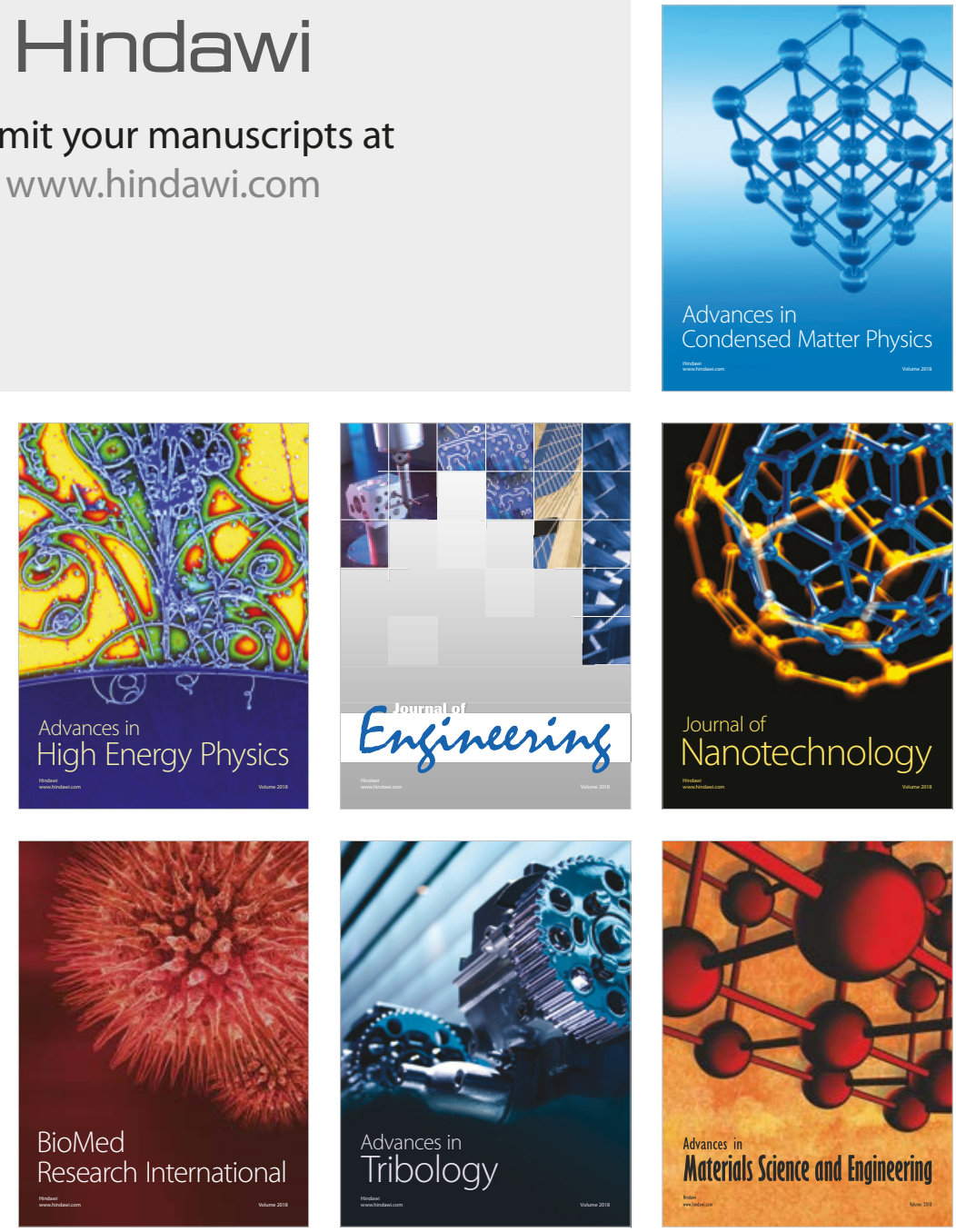